\title{
Effect of finishing and polishing on surface roughness of composite resins after bleaching
}

\author{
Bruna Fortes Bittencourt, Giovana Mongruel Gomes, Felipe Auer Trentini, Mônica Regina de Azevedo, \\ João Carlos Gomes, Osnara Maria Mongruel Gomes
}

Universidade Estadual de Ponta Grossa - UEPG, School of Dentistry, Area of Dental Materials, Ponta Grossa, PR, Brazil

\begin{abstract}
Aim: To evaluate the influence of finishing and polishing techniques on the surface roughness of two composite resins (CRs) subjected to bleaching procedure. Methods: Forty-eight CR specimens were divided into six groups $(n=8)$. For $G 1$ to $G 3$, a microhybrid CR (Opallis; FGM) was used, and G4 to G6, received a nanohybrid CR (Brilliant NewLine; Coltène/Whaledent). All specimens were subjected to bleaching procedure with $35 \%$ hydrogen peroxide (two 45-min applications, with a 5-day interval). The surface roughness of all specimens was evaluated before and after the bleaching and/or finishing/polishing (Ra parameter) by a roughness meter. After bleaching, the groups were subjected to finishing and polishing procedures: G2 and G5 - felt discs + diamond pastes; and G3 and G6 - silicon rubber tips. The control groups (G1 and G4) had no finishing or polishing treatment after bleaching. Data were analyzed by ANOVA and Tukey's posttest, and $t$ test for paired samples $(\alpha=0.05)$. Results: bleaching treatment increased Ravalues for the nanohybrid CR specimens, but both finishing/polishing techniques were able to reduce these values; for the microhybrid specimens, only finishing/polishing with silicon rubber tips decreased the roughness values. Conclusions: For both microhybrid and nanohybrid CRs, the silicon rubber tips were effective to reduce the surface roughness after bleaching procedure.
\end{abstract}

Keywords: composite resins; dental polishing; tooth bleaching.

\section{Introduction}

The beauty of the smile is extremely important in daily life. With aesthetics being increasingly valued, professionals use composite resins (CRs) as the first choice materials in dental offices, since these materials combine suitable mechanical properties with excellent aesthetics ${ }^{1}$.

In a parallel development, tooth bleaching modalities also became widely known and considered a safe and effective technique to treat discolored teeth ${ }^{2-3}$. Thus, in dental practice, it is common to have patients whose restorations will be subjected to bleaching procedures ${ }^{4}$. Therefore, a larger number of studies have been performed to confirm whether the bleaching agents may cause undesirable effects on dental tissues ${ }^{5-6}$ and restorations $s^{4,7-11}$. Therefore, it is important that dentists understand the consequences of these procedures on restorations' longevity, and to substitute ${ }^{8}$ or to maintain ${ }^{4}$ the CRs after bleaching, whenever required.

However, the decision to maintain or not the restoration depends on several factors, including marginal integrity, color and surface characteristics. Several studies have reported material-dependent surface roughness alterations of restorative materials after bleaching ${ }^{8,10-12}$. For the bleaching agent factors such as application time, $\mathrm{pH}$ and concentration may influence the topography ${ }^{8}$; for the composite, the organic matrix and particle size are the main factors related to surface alterations ${ }^{10}$. 
Surface smoothness of the restorations is one of the main factors of aesthetic success, since rough surfaces contribute to staining and bacteria deposition, and decreased brightness ${ }^{13}$. Thus, the surface roughness is an important property to evaluate the surface integrity of restorations, determining the polishing ability and wear rate of these materials ${ }^{14}$.

Final finishing and polishing are extremely important to increase the quality of restorations in oral function since they ensures surface smoothness and consequently, aesthetics and longevity ${ }^{15-16}$. After bleaching treatment, in particular, resin-based restorations should be carefully finished and polished in order to remove the outermost layer damaged by the bleaching agent. Based on this, the present study evaluated the influence of finishing and polishing techniques on the surface roughness of two CRs after bleaching. The null hypothesis was that finishing and polishing techniques do not influence the surface roughness of the bleached CRs.

\section{Material and methods}

Two brands of CRs were used: a microhybrid $(\mathrm{MH})$ Opallis (FGM, Joinvile, SC, Brazil) and a nanohybrid (NH) Brilliant NewLine (Coltène/Whaledent, Altstatten, Switzerland). The specimens were made using a metallic matrix $2 \mathrm{~mm}$ thick and $5 \mathrm{~mm}$ diameter. The surface smoothness of the specimens was standardized: the matrices were placed over a mylar strip (Mylar; DuPont, Wilmington, DE, USA) and a glass slide. The matrix was filled with $\mathrm{CR}$, and a new mylar strip was positioned over the composite/matrix set.
Then, another glass slide was used, and a $1 \mathrm{~kg}$ device was put on top of the glass slide, in order to obtain a flat and smooth composite surface. The weighing device and the upper glass slide were removed, and the specimens were light-cured for $20 \mathrm{~s}$ (LEDemetron; Kerr Corp., Orange, CA, USA) with a power intensity of $800 \mathrm{~mW} / \mathrm{cm}^{2}$.

After $48 \mathrm{~h}$, the initial roughness (IR) of all specimens was obtained in a digital roughness meter (Mitutoyo Surftest301; Mitutoyo-Kawasaki, Kanagawa, Japan). Five measures were performed on each specimen (one at the center and four in each quadrant, in a clockwise direction), and the arithmetic mean was obtained from these values. This mean was considered as the IR value. Surface roughness reading was performed using the $\mathrm{Ra}$ parameter $(\mu \mathrm{m})$ and the measuring profile ISO2001, a $0.25 \mathrm{~mm}$ cut-off, $1.25 \mathrm{~mm}$ in length and $0.1 \mathrm{~mm} / \mathrm{s}$ speed.

After the IR analysis, bleaching treatment was performed with $35 \%$ hydrogen peroxide (HP) (Whiteness HP Blue Calcium; FGM, Joinville, SC, Brazil), according to the manufacturer's instructions: two 45-min applications, with 5 days interval between each application. After the last bleaching agent application, the specimens were subjected to the finishing and polishing procedures, according to the CR and finishing/polishing treatment $(n=8)$ : for $G 2$ and G5: felt discs + diamond pastes (Felt Discs Diamond Flex and Diamond ACI, ACII and Diamond R; FGM, Joinville, SC, Brazil); G3 and G6: silicon rubber tips (Astropol; IvoclarVivadent, Schaan,Liechtenstein). The control groups G1 and G4 did not receive any finishing or polishing treatment (Figure 1). For G2 and G5, the specimen's surfaces were finished with a medium granulation paste (ACI) with the felt

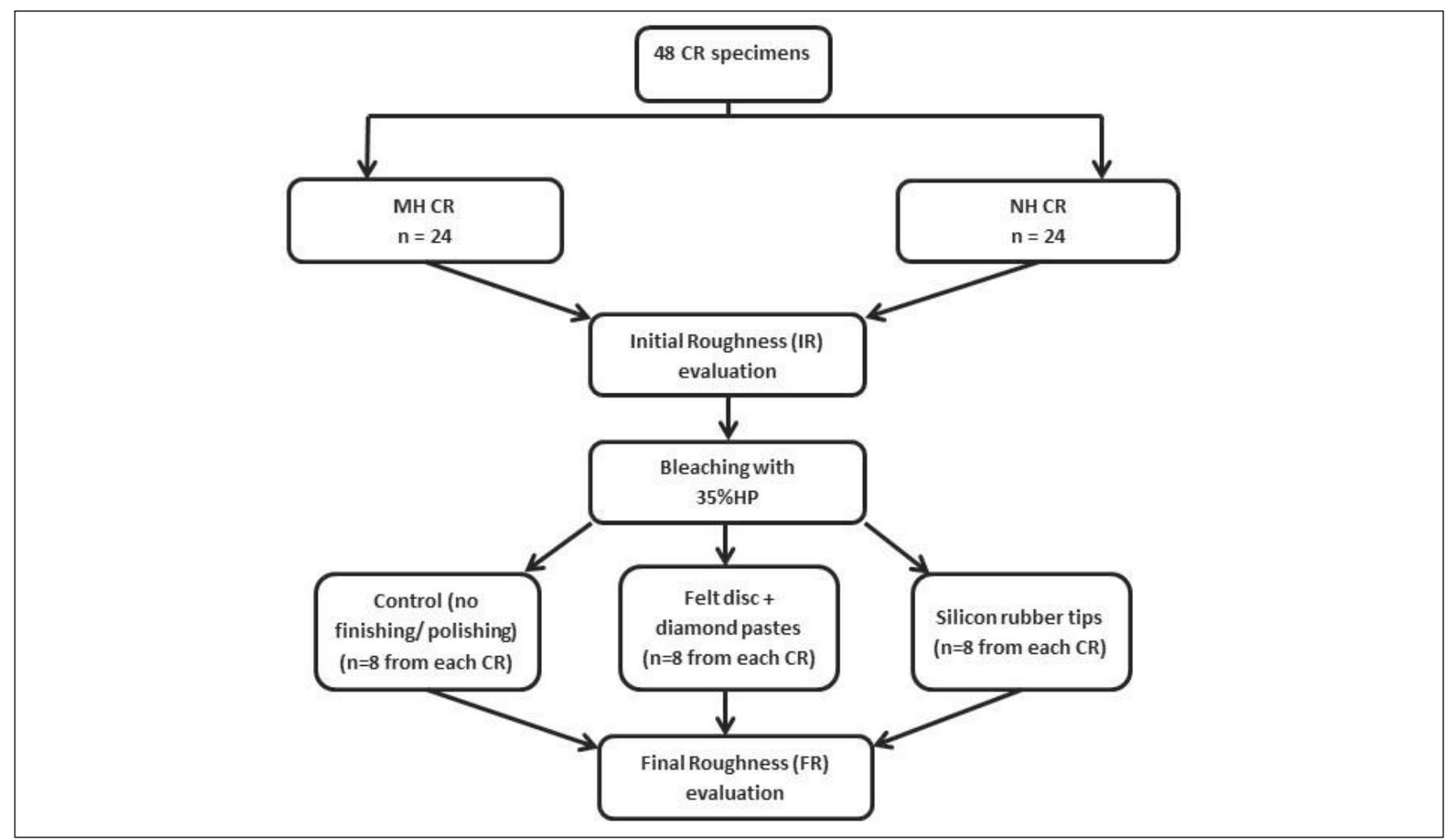

Fig. 1. Flowchart of the experimental design of the study. 
disc rotating at low-speed. The initial polishing of the specimens was carried out with small amount of the ACII paste (fine granulation) on the felt disc. Final polishing was achieved with the Diamond R paste with another felt disc.

For G3 and G6, the procedures were performed in three steps: Step 1 - finishing with Astropol F (gray) - with this tip, excess of material was removed and the rough surface of the restoration was smoothened; Step 2 - polishing with Astropol P (Green), in order to produce a complete final smooth surface; Step 3 - high-gloss polishing with Astropol HP (pink) - to produce a high-gloss surface. All tips were used at low speed. All materials, manufacturers and respective compositions used in this study are shown in Table 1.

For all groups that were subjected to finishing and polishing procedures, the materials were changed after use in every 2 specimens. All procedures were performed by a single calibrated operator, in an analytical balance, with a mean pressure of $0.2 \mathrm{kgf}$. All procedures were carried out under cold tap water to ensure removal of residues. Intermittent movements were applied and each instrument was used for 20 $\mathrm{s}$ to avoid cracks and grooves. The specimens were stored in artificial saliva at $37{ }^{\circ} \mathrm{C}$ (Benzoate $1 \mathrm{~g}$; CMC $10 \mathrm{~g}$; magnesium chloride $0.05 \mathrm{~g}$; potassium chloride $0.62 \mathrm{~g}$, sodium chloride $0.025 \mathrm{~g}$; sorbithol $42.74 \mathrm{~g}$, distilled water $944.53 \mathrm{~mL}$; dibasic potassium phosphate $0.8035 \mathrm{~g}$; monobasic potassium phosphate $0.326 \mathrm{~g}$ ), which was changed every day.

After $48 \mathrm{~h}$ of the final polishing, new surface roughness readings were performed in the same way as described for IR to obtain the final roughness values (FR). Data were analyzed statistically by ANOVA and Tukey's post-test for independent samples; and t test for paired samples (IR and FR of each group), confidence interval of $95 \%$ and $\alpha=0.05$.

\section{Results}

Mean values and standard deviation of IR and FR roughness (in $\mu \mathrm{m}$ ) for MHCR and NHCR are shown in Tables 2 and 3, respectively. No statistically significant differences were found between IR of all groups, for both MHCR $(p=0.95)$ and NHCR $(p=0.93)$.

Comparing the IR and FR values from G1 (MH CR), roughness values increased, but this difference was not statistically significant $(p=0.0769)$. There were no statistically significant differences between G2 and G1 ( $p>0.05)$, and G3 showed statistically significant lower final values compared with $\mathrm{G} 1(\mathrm{p} \leq 0.05)$. Comparing the different finishing and polishing procedures for $\mathrm{MH} \mathrm{CR}, \mathrm{G} 3$ presented lower roughness values than to $\mathrm{G} 2(\mathrm{p} \leq 0.05)$.

Comparing IR and FR from G4, it was observed that the bleaching procedure significantly increased the roughness values for NHCR $(p=0.0036)$. Analyzing the FR values for the finishing and polishing techniques, it may be observed that both G5 and G6 had lower values than the control group G4 $(\mathrm{p} \leq 0.05)$. G6 also had significantly lower final roughness values than $\mathrm{G} 5(\mathrm{p} \leq 0.05)$.

\section{Discussion}

After dental bleaching, it is necessary to evaluate some characteristics of $\mathrm{CR}$ restorations, such as color change, marginal integrity and surface roughness, in order to indicate the restoration maintenance or replacement. Surface roughness is an important parameter to be observed, since rough surfaces may appear after HP bleaching ${ }^{10}$. Roughness also influences aesthetic restoration, since it may lead to discoloration and wear, as well as biologic consequences to the periodontal health, especially the occurrence of secondary caries and gingivitis ${ }^{13}$.

During the specimen preparation in this study, a Mylar strip was used to produce specimens with standardized top surfaces ${ }^{15}$. After composite polymerization, the specimens covered with the mylar strips which did not receive any finishing/polishing before and after bleaching, were used as control group, as reported in other studies ${ }^{15,17-19}$.

In the present study, both CRs demonstrated increased surface roughness after bleaching procedures, as reported in previous studies ${ }^{7,20}$, but this alteration was significant only for the NHCR composite. Despite the commercial

Table 1. Materials used in the study

\begin{tabular}{|c|c|c|}
\hline Material & Manufacturer & Composition \\
\hline Composite resin Opallis & FGM, Joinville, SC, Brazil & $\begin{array}{c}\text { Bis-GMA, Bis-EMA, TEGDMA, silanized barium-aluminum glass and nanoparticles } \\
- \text { - particle size: } 40 \mathrm{~nm} \text { to } 3 \mu \mathrm{m}(78.5-79.8 \mathrm{wt} \%)\end{array}$ \\
\hline Composite resin Brilliant NewLine & $\begin{array}{l}\text { Coltène/Whaledent, Altstatten, } \\
\text { Switzerland }\end{array}$ & $\begin{array}{l}\text { Methacrylates, Dental glass -barium glass and amorphous silica - particle size: } \\
\qquad 0.04 \text { to } 2.8 \mu \mathrm{m}(77-78 \mathrm{wt} \%) .\end{array}$ \\
\hline Whiteness HPBlue & FGM, Joinville, SC, Brazil & $\begin{array}{l}35 \% \text { hydrogen peroxide, thickening agents, color mixtures, calcium gluconate, } \\
\text { glycol and deionized water }\end{array}$ \\
\hline $\begin{array}{l}\text { Diamond } \mathrm{Cl} \text { and } \mathrm{Cll} \\
\text { (medium and fine granulation) }\end{array}$ & FGM, Joinville, SC, Brazil & $\begin{array}{c}\text { Aluminum oxide (ACl: } 80 \mu \mathrm{m} ; \mathrm{AClI}: 30 \mu \mathrm{m} \text { ), Carbowax, thickeners, } \\
\text { mint essence, water }\end{array}$ \\
\hline Diamond R (extra-fine granulation) & FGM, Joinville, SC, Brazil & Aluminum oxide $(6-8 \mu \mathrm{m})$, Carbowax, thickeners, mint essence, water \\
\hline Astropol & $\begin{array}{l}\text { Ivoclar-Vivadent, } \\
\text { Schaan,Liechtenstein }\end{array}$ & $\begin{array}{l}\text { Caoutchouc, silicon carbide, aluminum oxide, titanium oxide, iron oxide (coarse } \\
\text { gray [45 mm], fine green [1 mm]);Caoutchouc, silicon carbide, aluminum oxide, } \\
\text { titanium oxide, iron oxide, diamond dust (extra-fine-pink [0.3 mm]) }\end{array}$ \\
\hline
\end{tabular}


Table 2. Mean values and standard deviation $( \pm)$ of initial (IR) and final (FR) surface roughness $(\mu \mathrm{m})$ for all experimental groups of the microhybrid composite resin $(*)$

\begin{tabular}{lll}
\hline Groups & Initial Roughness (IR) & Final Roughness (FR) \\
G1 & $0.282 \pm 0.295 \mathrm{Aa}$ & $0.427 \pm 0.419 \mathrm{Aa}$ \\
G2 & $0.290 \pm 0.173 \mathrm{Aa}$ & $0.263 \pm 0.114 \mathrm{Aa}$ \\
G3 & $0.274 \pm 0.174 \mathrm{Aa}$ & $0.135 \pm 0.040 \mathrm{Bb}$ \\
\hline
\end{tabular}

$\left.{ }^{*}\right)$ Lowercase letters indicate the comparisons within each column. Uppercase letters indicate the comparison within each row. Identical letters indicate statistically similar means $(p>0.05)$.

Table 3. Mean values and standard deviation $( \pm)$ of initial (IR) and final (FR) surface roughness $(\mu \mathrm{m})$ for all experimental groups of the nanohybrid composite resin (*)

\begin{tabular}{lll}
\hline Groups & Initial Roughness (IR) & Final Roughness (FR) \\
G4 & $0.463 \pm 0.234 \mathrm{Aa}$ & $0.654 \pm 0.326 \mathrm{Bb}$ \\
G5 & $0.457 \pm 0.184 \mathrm{Aa}$ & $0.242 \pm 0.072 \mathrm{Bc}$ \\
G6 & $0.476 \pm 0.264 \mathrm{Aa}$ & $0.174 \pm 0.082 \mathrm{Bd}$
\end{tabular}

${ }^{*}$ ) Lowercase letters indicate the comparisons within each column. Uppercase letters indicate the comparison within each row. Identical letters indicate statistically similar means $(p>0.05)$.

nomenclature, both CRs used in this study have the same medium particle size: $0.5 \mu \mathrm{m}$ for the MHCR (Opallis) and $0.6 \mu \mathrm{m}$ for the NHCR (Brilliant NewLine). It is known that bleaching agents may act mainly on the resinous matrix of CRs whereas the inorganic particles are inert, even in an acidic environment ${ }^{7}$. This suggests that matrix erosion occurs, with the consequent displacement of inorganic particles. In this study, both CRs also have the same mass fraction, approximately $77 \mathrm{wt} \%$. A previous study reported that the presence of lower filler amount and greater organic matrix content makes the CRs more susceptible to erosive action by the bleaching agents, leading to particle exposure and crack formation ${ }^{20}$.

For the NHCR Brilliant NewLine, both finishing/ polishing procedures were able to decrease the surface roughness of the bleached specimens. However, in this study, better results were found when silicon rubber tips were used, as demonstrated elsewhere ${ }^{21}$. These results are probably due to the increased abrasiveness of silicon rubber tips compared to diamond pastes, removing the roughness caused by bleaching treatment on the top layer of the CRs. Another hypothesis to explain the results may be the composition of the Astropol tips. Hence, the abrasiveness of the used finishing/polishing system may directly influence the restoration's final roughness ${ }^{21}$. On the other hand, researchers have found that Astropol system caused the highest roughness values on CRs compared to several finishing/polishing procedures $^{22}$, due to its abrasive potential. In this case, a bleaching treatment was not performed before the finishing and polishing procedure; in other words, there was no previous rougher surface.

Particle type and size of CRs may influence the surface roughness ${ }^{23}$, determining the final polishing of the restorations ${ }^{24-25}$. However, some material's intrinsic factors, like the resin monomer composition and filler content also play a critical role in the clinical behavior of these restorative materials ${ }^{18}$. Berger et al. ${ }^{18}$, reported that the most appropriate technique would be the use of a CR and finishing/polishing agent developed by the same manufacturer, since the use of these agents depend on the filler hardness, size and content of each resin; and those features the manufacturer must know. This study encourages further investigations to evaluate CRs with different inorganic particle size and weight.

It is important to note that this is an in vitro study, and it has limitations. Only the surface roughness of CR was analyzed, without concerning with aesthetic factors. Bleaching agents may affect the color of existing composite restorations ${ }^{26}$. So, when dealing with anterior restorations, not only the topography, but also the aesthetics of the restoration should be evaluated, in order to indicate the correct restorative procedure.

As recently reported, bleaching may cause increased surface roughness on composite materials, and the clinicians should be aware whether the CR restoration will be exposed to a bleaching procedure ${ }^{27}$. However, if there is an optimal finishing and/or polishing procedure, this seems to have no clinical significance ${ }^{27-28}$. This study demonstrated that despite the alterations in the surface roughness of CRs by the bleaching procedure, maintenance of these restorations might be indicated if there is no aesthetic involvement. Finishing and polishing techniques are effective to reduce bleaching adverse effects CR surface roughness. Specifically, the silicon rubber tips showed satisfactory results for both MHCR and NHCR after bleaching procedure.

According to the results of this study, it may be concluded that for the MHCR, only the finishing and polishing procedure with silicon rubber tips reduced the roughness values of these restorations after bleaching. For the NHCR, both finishing and polishing techniques were able to reduce roughness values of restorations after bleaching, and the silicon rubber tip technique was more effective than felt discs and diamond pastes.

\section{References}

1. Mitra SB, Wu D, Holmes BN. An application of nanotechnology in advanced dental materials. JAm Dent Assoc. 2003; 134: 1382-90.

2. Kwon SR. Whitening the single discolored tooth. Dent Clin North Am. 2011; 55: 229-39.

3. Li Y. Safety controversies in tooth bleaching. Dent Clin North Am. 2011; 55: 255-63.

4. Polydorou O, Mönting JS, Hellwig E, Auschill TM. Effect of in-office tooth bleaching on the microhardness of six dental esthetic restorative materials. Dent Mater. 2007; 23: 153-8.

5. Zantner C, Beheim-Schwarzbach N, Neumann K, Kielbassa AM. Surface microhardness of enamel after different home bleaching procedures. Dent Mater. 2007; 23: 243-50.

6. Cavalli V, Rodrigues LK, Paes-Leme AF, Soares LE, Martin AA, Berger $\mathrm{SB}$, et al. Effects of the addition of fluoride and calcium to low-concentrated carbamide peroxide agents on the enamel surface and subsurface. Photomed Laser Surg. 2011; 29: 319-25.

7. Moraes RR, Marimon JL, Schneider LF, Correr-Sobrinho L, Camacho GB, Bueno M. Carbamide peroxide bleaching agents: effects on surface roughness of enamel, composite and porcelain. Clin Oral Invest. 2006; 10: 23-8. 
8. Gurgan S, Yalcin F. The effect of 2 different bleaching regimens on the surface roughness and hardness of tooth-colored restorative materials. Quintessence Int. 2007; 38: 83-7.

9. Mujdeci A, Gokay O. Effect of bleaching agents on the microhardness of tooth-colored restorative materials. J Prosthet Dent. 2008; 95: 286-9.

10. Dutra RA, Branco JR, Alvim HH, Poletto LT, Albuquerque RC. Effect of hydrogen peroxide topical application on the enamel and composite resin surfaces and interface. Indian J Dent Res. 2009; 20: 65-70.

11. Yu H, Li Q, Cheng $\mathrm{H}$, Wang $\mathrm{Y}$. The effects of temperature and bleaching gels on the properties of tooth-colored restorative materials. J Prosthet Dent. 2011; 105: 100-7.

12. Lima DA, De Alexandre RS, Martins AC, Aguiar FH, Ambrosano GM, Lovadino JR. Effect of curing lights and bleaching agents on physical properties of a hybrid composite resin. J Esthet Restor Dent. 2008; 20: 266-75.

13. Heintze SD, Forjanic M, Ohmiti K, Rousson V. Surface deterioration of dental materials after simulated tooth brushing in relation to brushing time and load. Dent Mater. 2010; 26: 306-19.

14. Tanoue N, Matsumura $\mathrm{H}$, Atsuta $\mathrm{M}$. Wear and surface roughness of current prosthetic composites after toothbrush/dentifrice abrasion. J Prosthet Dent. 2000; 84: 93-7.

15. Rai R, Gupta R. In vitro evaluation of the effect of two finishing and polishing systems on four esthetic restorative materials. J Conserv Dent. 2013; 16: 564-7.

16. Barakah HM, Taher NM. Effect of polishing systems on stain susceptibility and surface roughness of nanocomposite resin material. J Prosthet Dent. 2014 Apr 7. pii: S0022-3913(14)00045-6. doi: 10.1016/ j.prosdent.2013.12.007. (in press).

17. Korkmaz Y, Ozel E, Attar N, Aksoy G. The influence of one-step polishing systems on the surface roughness and microhardness of nanocomposites. Oper Dent. 2008; 33: 44-50.

18. Berger SB, Palialol AR, Cavalli V, Giannini M. Surface roughness and staining susceptibility of composite resins after finishing and polishing. J Esthet Restor Dent. 2011; 23: 34-43.

19. Schmitt VL, Puppin-Rontani RM, Naufel FS, Ludwig D, Ueda JK, CorrerSobrinho $L$. Effect of finishing and polishing techniques on the surface roughness of a nanoparticle composite resin. Braz J Oral Sci. 2011; 10: 105-8.

20. Turker SB, Biskin T. Effect of three bleaching agents on the surface properties of three different esthetic restorative materials. J Prosthet Dent. 2003; 89: 466-73.

21. Marghalani HY. Effect of finishing/polishing systems on the surface roughness of novel posterior composites. J Esthet Restor Dent. 2010; 22: 127-38.

22. Paravina RD, Roeder L, Lu H, Vogel K, Powers JM. Effect of finishing and polishing procedures on surface roughness, gloss and color of resinbased composites. Am J Dent. 2004; 17: 262-6.

23. Marghalani HY. Effect of filler particles on surface roughness of experimental composite series. J Appl Oral Sci. 2010; 18: 59-67.

24. Reis AF, Giannini M, Lovadino JR, Ambrosano GM. Effects of various finishing systems on the surface roughness and staining susceptibility of packable composite resins. Dent Mater. 2003; 19: 12-8.

25. Takanashi E, Kishikawa R, Ikeda M, Inai N, Otsuki M, Foxton RM, et al. Influence of abrasive particle size on surface properties of flowable composites. Dent Mater J. 2008; 27: 780-6.

26. Canay $S$, Cehreli MC. The effect of current bleaching agents on the color of light-polymerized composites in vitro. J Prosthet Dent. 2003; 89: 474-8.

27. $\mathrm{Yu} \mathrm{H}, \mathrm{Li} \mathrm{Q}$, Wang YN, Cheng $\mathrm{H}$. Effects of temperature and in-office bleaching agents on surface and subsurface properties of aesthetic restorative materials. J Dent. 2013; 41: 1290-6.

28. Markovic L, Jordan RA, Glasser MC, Arnold WH, Nebel J, Tillmann W, et al. Effects of bleaching agents on surface roughness of filling materials. Dent Mater J. 2014; 33: 59-63. 